\title{
RESTORING THE PRINCIPLE OF MINIMUM DIFFERENTIATION IN PRODUCT POSITIONING
}

\author{
BYong-DuK RHEE
}

John M. Olin School of Business

Washington Unizersity

St. Louis, MO 63130

André de Palma

Département COMIN

Université de Genève

Genève, CH-1211, Switzerland

Claes Fornell

Graduate School of Business Administration

The University of Michigan

Ann Arbor, MI 48109

JaCQUes-François Thisse

Université de Paris I and CERAS,

Ecole Nationale des Ponts et Chaussées

Paris, F-75343, France

\begin{abstract}
Most research on product positioning supports the idea of differentiation. Product standardization (i.e., minimum differentiation) occurs only under very limiting assumptions. Yet, similar products are often observed in the marketplace. We attempt to restore the case for standardization by using more realistic assumptions than in previous work. We assume that consumers consider not only observable attributes in brand choice, but also attributes that are unobservable by the firms. We find that standardization is an equilibrium when consumers exhibit sufficient heterogeneity along the unobservable attributes under both positioning with exogenously given prices and price competition. We also show that, under insufficient heterogeneity along the unobservable attribute, our results coincide with past research that argues in favor of differentiation.
\end{abstract}

The authors wish to thank the anonymous reviewers for their valuable comments and suggestions to improve the quality of this paper. Special thanks should be extended to the editor, Daniel F. Spulber, for encouraging this research. The second author would like to thank Robin Lindsey at the University of Alberta for helpful discussion and his comments, and thanks Centre Interuniversitaire de Management, Belgium, for funding.

(c) 1993 The Massachusetts Institute of Technology.

Journal of Economics \& Management Strategy, Volume 1, Number 3, Fall 1992 


\section{INTRODUCTION}

Perhaps the most fundamental decision in product positioning is that of differentiation versus standardization. The latter refers to a position similar to competition; the former is the offering of uniqueness. Clearly, the decision to position a product close to competition (or away from it) predicates many other decisions, and has significant consequences for production, marketing, and long-term market performance of the product. Even though the issue is extensively treated in textbooks (e.g., Kotler, 1991; Porter, 1980) and is an important element in marketing models of competition (for an extensive review, see Eliashberg and Chatterjee, 1985, and Moorthy, 1985), it remains a hotly debated topic. When should a differentiation strategy be pursued? Under what conditions would standardization be better?

Obviously, the issue is not merely an empirical question. Advancement in theory is also called for. This is not to suggest that the problem of differentiation/standardization is currently devoid of theoretical approaches. In fact, the opposite is true. Ever since the publication of Harold Hotelling's paper, "Stability in Competition," in 1929, there has been a steady stream of research in economics on the nature of competition in terms of standardization/differentiation. Recently, marketing scholars have also made contributions (Carpenter, 1989; Hauser and Shugan, 1983; Moorthy, 1988). Most of this work has followed a game-theoretic approach.

We aim to continue this tradition. We also hope to add to it by incorporating somewhat more realistic assumptions than have previously been the case and by examining several different competitive situations. Specifically, we allow for consumer heterogeneity and incorporate the notion of unobservable attributes influencing consumer choice. We consider a linear utility loss caused by consuming a product away from the ideal point. Further, two scenarios are investigated: positioning under exogenously given prices and positioning under price competition. When prices are given, the $n$-firm case is examined; positioning with price competition is analyzed in the context of duopoly.

Overall, we have strived to move the investigation toward added realism, which, of course, is important in its own right. What matters more, however, are the results from utilizing less stringent assumptions. In this case, our results are noteworthy: Previous findings are either overturned or amplified in the sense that a cogent case can now be made for minimum differentiation along the observable attribute despite the flaw in Hotelling's original formulation and the general opposition from previous literature. Previous research is re- 
plete with evidence on the failings of the principle of minimum differentiation; yet we are able to restore this principle under both exogenously given prices as well as price competition. The conduit here is the unobservable attribute. We no longer require firms to be fully informed about which attributes consumers use in making their choices. When firms are uncertain enough about predicting choices, they will tend to pursue a strategy of minimum differentiation.

Before we summarize the literature on this subject, it will be helpful to clarify the idea of observable versus unobservable attributes and their implications for demand and profit in a formal model. Subsequently, we examine the literature on positioning under exogenously given prices, which does not support minimum differentiation. We submit our proof to the contrary, that is, a positional equilibrium exists at the market center under sufficient consumer heterogeneity along the unobservable attribute. Next, we analyze positioning with price competition in a two-stage game framework. Again, we review the literature (which does not support minimum differentiation) before a formal investigation. We show the existence of price equilibrium in pure strategies (under sufficient consumer heterogeneity along the unobservable attribute) in the second stage of the game. In the first stage, equilibrium positions are investigated. The complexity of this problem requires numerical computations, but the support for the principle of minimum differentiation remains.

\section{OBSERVABLE AND UNOBSERVABLE ATtRIBUTES IN MODELING THE CONSUMER}

We assume a market where there are $n$ brands, and consumers purchase one unit of product per period. Consumer tastes are heterogeneous and characterized by two attributes (or perceptual dimensions), $X$ and $Y$. The first attribute, $X$, represents characteristics observable to the firms. This attribute is modeled in the standard Hotelling (1929) paradigm. Different tastes across consumers on the attribute are described in terms of different ideal points (Coombs, 1950). It is assumed that there is a continuum of consumers uniformly distributed on the interval $I \equiv[0,1]$ with differing tastes. As Lancaster (1979, p. 47) points out, while such a distribution is empirically rare, it provides a background in which parametric variations of more immediate interest and importance can be investigated. That is, the assumption of uniform tastes has the advantage of eliminating the effect of nonuniformity of tastes as a possible explanation of equilibrium product positioning (Moorthy, 1988). A nonuniform taste distribution (e.g., 
unimodal or bimodal) may lead to standardizing or differentiating (Neven, 1986), and confounds the effect of competition, which is what we wish to analyze.

Because the attribute is observable (known) and measurable by the firms, they are able to position their products strategically on this attribute. It is assumed that consuming a product away from the ideal point along the observable attribute incurs a linear utility loss. Specifically, when a consumer with ideal point $x \in I$ consumes product $i$ containing the attribute level $x_{i} \in I$, the consumer utility is reduced by $\delta\left|x_{i}-x\right|$, where $\delta>0$ is the importance weight associated with the observable attribute (Wilkie and Pessemier, 1973). ${ }^{1}$

The second attribute, $Y$, represents the characteristics that are unobservable or unmeasurable to the firms but considered by consumers in choosing a product. Unobservability of the attribute generates uncertainty in predicting choices on the part of the firms. Choices are affected not only by judgments but also by situational factors that make prediction difficult (Hogarth, 1987). Consumer variety seeking also complicates firms' ability to predict (McAlister, 1982). In addition, some consumer-specific characteristics may not be fully observable or measurable even with marketing research and may cause further difficulties in predicting choices (Bass, Jeuland, and Wright, 1976). The uncertainty may result from the firms' lack of knowledge about consumer behavior and preferences in evaluating ideal points and utility loss (Manski, 1977). Although the observable attribute may account for a significant portion of heterogeneous preferences, the firms may mistake these diverse preferences for heterogeneity along the unobservable attribute caused by faulty marketing knowledge and research skills. The attribute $Y$ captures these unpredictable choice heterogeneities resultant from situational, variety seeking, consumer-specific characteristics, and the firms' lack of marketing knowledge.

A consumer of type $y \in \mathscr{R}$ on this attribute has valuation $e_{i}(y)$ of product $i$, which is unknown to the firms. We assume that there is no correlation between these two types of attributes. Therefore, in consuming product $i$, a consumer of type $(x, y)$ obtains the following (indirect) utility:

$$
U_{i}(x, y)=R(x)-p_{i}-\delta\left|x_{i}-x\right|+e_{i}(y)
$$

1. Alternatively, consumer utility can be modeled using a quadratic utility loss as in d'Aspremont et al. (1979). However, the nature of the problem remains the same even in the quadratic case, and we obtain fundamentally identical results. A detailed formal investigation in the quadratic case is available from the authors upon request. 
where $R(x)$ is a positive constant and may be interpreted as gross benefits that a consumer of type $x$ can obtain from the observable attribute in consuming a unit of the product and $p_{i}$ is the price charged by firm $i$.

Because $e_{i}(y)$ is unknown to the firms, the firms are limited in their ability to predict each consumer's choice. Firms can only have access to information regarding the consumer utility on the observable attribute. The utility along the unobservable attribute, $e_{i}(y)$, may be viewed as the realization of a random variable $\epsilon_{i} \cdot{ }^{2}$ Therefore, the best the firms can do is to evaluate the probability that a consumer of type $x$ on the observable attribute chooses one product over another. The probability $\operatorname{Pr}_{i}(x)$ that a consumer of type $x$ will purchase product $i$ is

$$
\left.\operatorname{Pr}_{i}(x)=\operatorname{Pr} \mid U_{i}(x, y) \geq U_{j}(x, y) ; \text { all } j \neq i\right] .
$$

The probabilistic choice model was developed as a stochastic utility model based on Luce's (1959) choice axiom (i.e., the multinomial logit [McFadden, 1974]) and Thurstone's (1927) law of comparative judgment (i.e., the multinomial probit [Daganzo, 1979]). Anderson et al. (1988) proved that the multinomial logit can be derived from an entropic utility function in the representative consumer approach of Dixit and Stiglitz (1977) and Spence (1976). It is also shown that general probabilistic choice models may be derived from a population of heterogeneous consumers where their valuations of the unobservable attributes are assigned some distribution (e.g., logistic or normal) (Anderson, de Palma, and Thisse, 1989). The interpretation is that the probabilistic choice model may represent both a particular consumer who tries various brands over a long period of time and heterogeneous choices within a consumer population. Because the behavioral support for such probabilistic choice is more compelling than for a deterministic one (Schmalensee and Thisse, 1988), the probabilistic choice model has been widely applied in various marketing studies (e.g., Guadagni and Little, 1983; Kamakura and Srivastava, 1986; and Punj and Staelin, 1978, to mention a few).

For a duopoly, the probability $\operatorname{Pr}_{i}(x)$ becomes

$$
\operatorname{Pr}_{i}(x)=\operatorname{Pr}\left[\epsilon \geq p_{i}-p_{j}+\delta\left|x_{i}-x\right|-\delta\left|x_{j}-x\right|\right],
$$

2. An alternative interpretation of $\epsilon_{\mathrm{i}}$ is that of a random disturbance in the stochastic ideal point model (DeSoete, Carroll, and DeSarbo 1986): $\bar{x}=x+e$, where $\bar{x}$ is the ideal point revealed in choice, $x$ the ideal point measured in marketing research, and $e$ the disturbance representing the randomness of the ideal point locations. This interpretation explains the case in which consumers show unstable ideal points. 
where $\epsilon=\epsilon_{i}-\epsilon_{i}$. The choice probability is monotonically increasing with respect to utility along the observable attribute. In order to compute choice probabilities, the firms need to specify a distribution function for $\epsilon$. The normal distribution is an obvious candidate due to the central limit theorem. It, however, does not yield a tractable form for the choice probability. On the other hand, it is well known that the logistic distribution closely approximates the normal and also provides a closed-form expression for the choice probability (Ben-Akiva and Lerman, 1985).

We assume that $\epsilon$ has a logistic distribution with mean zero and standard deviation $\pi \sigma / \sqrt{3}$. Hence, $\sigma>0$ can be viewed as measuring the degree of uncertainty due to consumer heterogeneity along the unobservable attribute. ${ }^{3}$ When $\sigma=0$, consumer tastes are homogeneous along the unobservable attribute, but heterogeneous along the observable attribute. Consumers patronize the product closest to their tastes on the observable attribute as in Hotelling (1929). Therefore, the firms can correctly predict each consumer's choice with the distance between the ideal point and the firms' positions on the observable attribute. As consumer heterogeneity increases along the unobservable attribute, the firms predict each consumer's choice with less certainty. That is, the probability of correct prediction decreases. If consumer tastes are very heterogeneous along the unobservable attribute $(\sigma \rightarrow \infty)$, the firms cannot predict consumer choices. The firms will get identical choice probabilities of $1 / n$ over the entire market.

\section{PRofits and Demands}

We will analyze profits and demands in the context of duopoly. It is assumed that the firms are risk-neutral and noncooperatively maximize their profits. Each firm offers one product. The firms compete on price and position on the observable attribute, $X$. Without loss of generality, firm $i$ is assumed to position to the left of firm $j$. When firm $i$ positions at $x_{i}$ and firm $j$ at $x_{j}$ on the observable attribute, where $x_{i} \leq$ $x_{j}$, the intervals $\left[0, x_{i}\right],\left[x_{i}, x_{j}\right]$, and $\left[x_{j}, 1\right]$ are named regions $L($ Left $), C$ (Center), and $R$ (Right), respectively. We assume that both firms have identical cost structures. This assumption allows us to rule out the trivial case in which product differentiation arises from technological differences between the firms (Moorthy, 1988). Marginal costs are

3. $\sigma$ may also be viewed as the importance weight associated with the unobservable attribute. We implicitly assume that the firms access the same information so that they model $\bullet$ in the same manner. 
constant and normalized to zero. Fixed costs are not considered in this paper.

When $\epsilon$ follows a logistic distribution with mean zero and standard deviation $\pi \sigma / \sqrt{3}$, the choice probability $\operatorname{Pr}_{i}^{k}(x)$ that a consumer of type $x$ in the region $k$ will purchase product $i$ is as follows:

$$
\begin{aligned}
& \operatorname{Pr}_{i}^{L}(x)=\left\{1+\exp \left[\frac{p_{i}-p_{j}+\delta\left(x_{i}-x_{j}\right)}{\sigma}\right]\right\}^{-1}, \\
& \operatorname{Pr}_{i}^{C}(x)=\left\{1+\exp \left[\frac{p_{i}-p_{j}+\delta\left(2 x-x_{i}-x_{j}\right)}{\sigma}\right]\right\}^{-1}, \\
& \operatorname{Pr}_{i}^{R}(x)=\left\{1+\exp \left[\frac{p_{i}-p_{j}+\delta\left(x_{j}-x_{i}\right)}{\sigma}\right]\right\}^{-1} .
\end{aligned}
$$

Figure 1 illustrates the choice probability in three regions. Note that $\operatorname{Pr}_{i}^{k}(x)=1-\operatorname{Pr}_{i}^{k}(x)$ and that the probability of purchasing product $i$ or $j$ is invariant in $x$ over regions $L$ and $R$. Because

$$
\frac{\partial \operatorname{Pr}_{i}^{C}(x)}{\partial x}<0
$$

the choice probability is monotonically decreasing for product $i$, whereas it is increasing for product $j$ in region $C$. Further,

$$
\operatorname{Sign} \frac{\partial^{2} \operatorname{Pr}_{i}^{\complement}(x)}{\partial x^{2}}=\operatorname{Sign}\left\{\exp \left[\frac{p_{i}-p_{j}+\delta\left(2 x-x_{i}-x_{j}\right)}{\sigma}\right]-1\right\} .
$$

The inflection point of $\operatorname{Pr}_{i}^{\mathcal{C}}(x)$ is at

$$
\hat{x}=\frac{x_{i}+x_{j}}{2}-\frac{p_{i}-p_{j}}{2 \delta} .
$$

$\operatorname{Pr}_{i}^{C}(x)\left(\operatorname{Pr}_{i}^{C}(x)\right)$ is strictly concave (convex) over $x_{i} \leq x \leq \hat{x}$, and strictly convex (concave) over $\hat{x} \leq x \leq x_{i}$. Consumers to the left of the inflection point have a higher probability of purchasing product $i$, whereas consumers to the right have a higher probability of purchasing product $j$. A consumer at the inflection point has identical probabilities of purchasing either product $\left(\operatorname{Pr}_{i}^{\mathcal{C}}(\hat{x})=\frac{1}{2}\right)$. Further, an increase in price by firm $i$ moves the inflection point toward the left, whereas price increase by firm $j$ moves it toward the right.

As $\delta$ approaches zero, the choice probability becomes a binary logit:

$$
\operatorname{Pr}_{i}(x)=\frac{\exp \left[-p_{i} / \sigma\right]}{\exp \left[-p_{i} / \sigma\right]+\exp \left[-p_{i} / \sigma\right]} .
$$




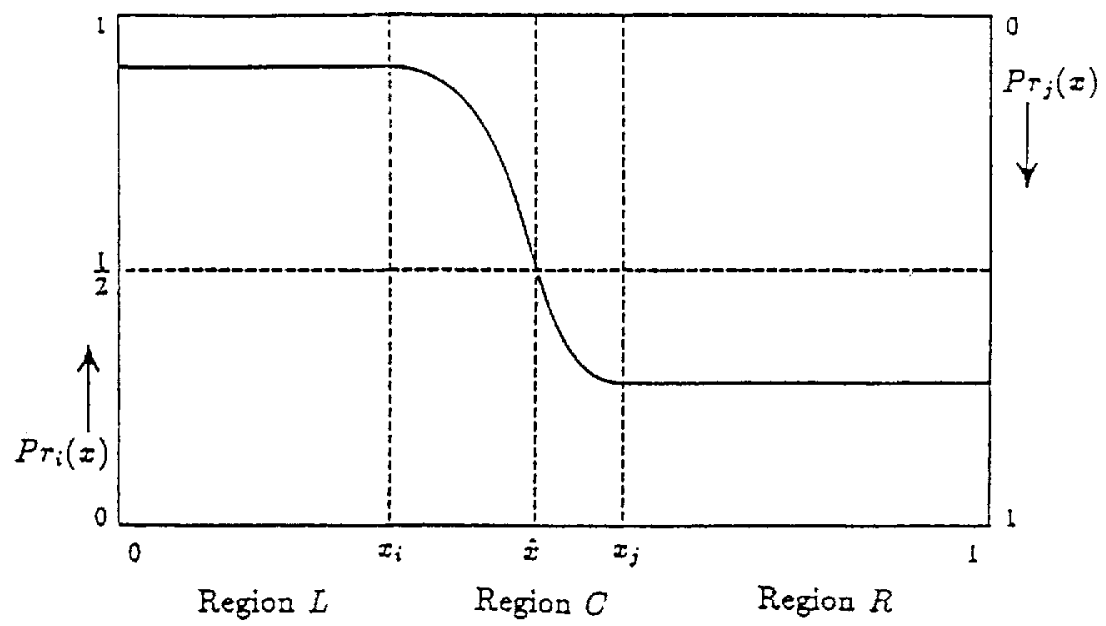

FIGURE 1. THE CHOICE PROBABILITY THAT A CONSUMER IN EACH REGION WILL PURCHASE A PRODUCT FROM FIRM I OR J.

Because

$$
\frac{\partial \operatorname{Pr}_{i}(x)}{\partial \sigma} \frac{\geq}{<} 0 \quad \text { for } x \frac{>}{<},
$$

the choice probability becomes flatter at $\operatorname{Pr}_{1}(x)=\frac{1}{2}$ as the degree of uncertainty $(\sigma)$ increases. Figure 2 illustrates the effect of $\sigma$ on the choice probability. When $\sigma=\infty$, the choice probability of either product is $\frac{1}{2}$, and both firms always expect half of the market, regardless of positions and prices. On the other hand, as $\sigma$ approaches zero, the probabilistic choice becomes a deterministic one (as in Hotelling, 1929):

$$
\operatorname{Pr}_{i}(x)=\left\{\begin{array}{l}
1 \text { if } x \leq \hat{x} \\
0 \text { if } x>\hat{x}
\end{array}\right.
$$

Consumers always purchase the product with maximum utility along the observable attribute. Hence, all consumers to the left of the inflection point patronize product $i$, and all consumers to the right patronize product $j$.

Given that consumer tastes are uniformly distributed on the observable attribute $X \in I$, each firm's expected demand is as follows:

$$
Q_{i}=\int_{0}^{x_{i}} \operatorname{Pr}_{i}^{\perp}(x) d x+\int_{x_{i}}^{x_{i}} \operatorname{Pr}_{i}^{C}(x) d x+\int_{x_{i}}^{1} \operatorname{Pr}_{i}^{R}(x) d x
$$




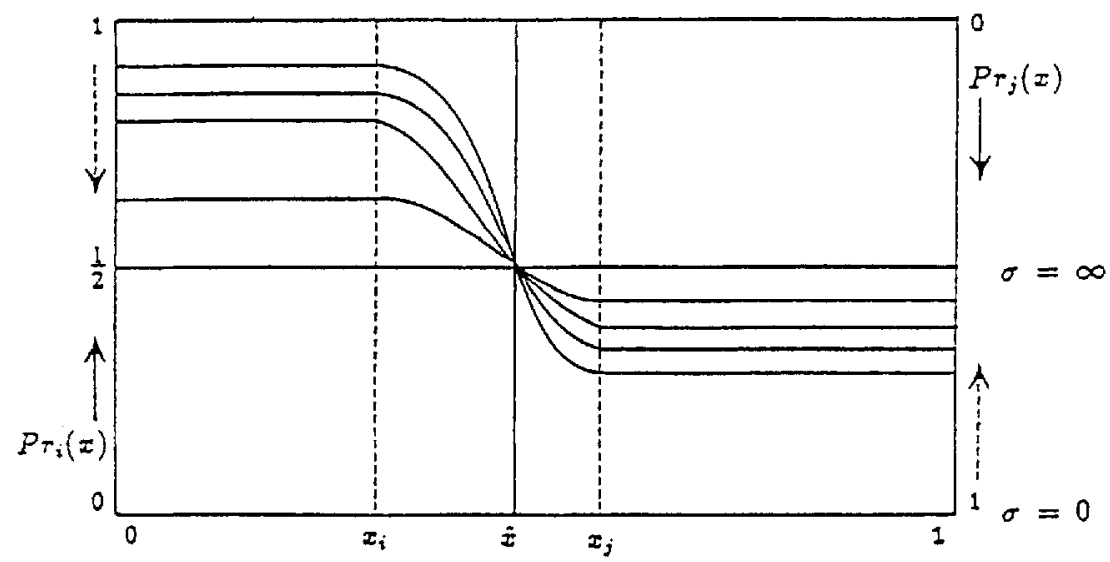

FIGURE 2. THE EFFECT OF CONSUMER HETEROGENEITY ALONG THE UNOBSERVABLE ATTRIBUTE ON THE CHOICE PROBABILITY.

$$
\begin{aligned}
& =a x_{i}+b\left(1-x_{j}\right)+\left(x_{j}-x_{i}\right)-\frac{\sigma}{2 \delta} \ln \left(\frac{a}{b}\right) \\
Q_{j} & =\int_{0}^{x_{i}} \operatorname{Pr}_{j}^{L}(x) d x+\int_{x_{i}}^{x_{j}} \operatorname{Pr}_{j}^{C}(x) d x+\int_{x_{j}}^{1} \operatorname{Pr}_{j}^{R}(x) d x \\
& =1-Q_{i}
\end{aligned}
$$

where

$$
\begin{aligned}
& a \equiv\left\{1+\exp \left[\frac{p_{i}-p_{j}-\delta\left(x_{j}-x_{i}\right)}{\sigma}\right]\right\}^{-1} \\
& b \equiv\left\{1+\exp \left[\frac{p_{i}-p_{j}+\delta\left(x_{j}-x_{i}\right)}{\sigma}\right]\right\}^{-1} .
\end{aligned}
$$

Each firm's market share is equivalent to its demands in the normalized consumer market. Under the assumption of constant (zero) marginal costs, the expected profits are:

$$
\Pi_{i}=p_{i} Q_{i} \quad \text { and } \quad \Pi_{j}=p_{i} Q_{j} .
$$

The expected profits are continuous functions of position and price over the strategy set, $I^{2} \times \mathscr{R}^{2}$, as long as $\sigma>0$. 


\section{PRODUCT POSITIONING UNDER EXOGENOUSLY GIVEN PRICES}

Price has often been regulated by governments to protect consumers and small competitors from dominant firms and to provide politically effective interest groups with benefits. ${ }^{4}$ Price regulation has been documented in the following industries: airlines (Schmalensee, 1977), trucking (Mentzer and Gomes, 1986), railroads (Boyer, 1977), insurance (Ippolito, 1979), natural gas (MacAvoy and Pindyck, 1973), telecommunications (Marks, 1988), milk (Ippolito and Masson, 1978), cable TV, etc. Firms sometimes tacitly fix price or follow the price set by a dominant firm to alleviate competition in oligopolistic markets. When price competition is restricted, whether voluntarily or by government regulations, firms actively engage in nonprice competition. We review the literature on product competition under exogenously given prices and examine the impact of consumer heterogeneity on product positioning.

It is broadly accepted in marketing that consumers consider not only price but also various attributes in choosing a product (Wilkie and Pessemier, 1973). When consumer tastes are heterogeneous on those attributes, some consumers would prefer to buy a product from one seller over another even though the preferred seller may charge a higher price. When price competition is restricted, product differentiation based only upon those attributes thus leads to nonprice competition.

Optimal product positioning (or product design) under heterogeneous consumer tastes has been examined in the Hotelling paradigm (de Palma et al., 1985, 1987, 1989; Eaton and Lipsey, 1975; Hotelling, 1929; Lerner and Singer, 1937; Prescott and Visscher, 1977). Lerner and Singer (1937) incorporates nonprice competition into the Hotelling framework with an attribute that consumers consider in choosing a product. Consumers prefer to consume close to their ideal points. Under the assumption of inelastic demand, the "principle of minimum differentiation" emerges as an equilibrium when two firms charge identical prices: The firms position at the market center with an infinitesimal distance between them. This is so because the proximity of the

4. There are two main theories of economic regulation: "public interest" and "capture" theories. In public interest theory, economic regulation is thought of as resultant from the response to the demand of the public for the correction of inefficient or inequitable market practice. Capture theory, on the other hand, holds that regulation is caused by the demands of interest groups struggling among themselves to maximize the benefits of their members. For more details, see Joskow and Noll (1981). 
other firm has no negative effect on price (which is exogenously given). Hence, each firm increases profits as it approaches the competitor's position. If the firms position at noncentral locations (with an infinitesimal distance between them), the firm on the smaller side of the market has an incentive to choose a position next to the competitor on the larger side ("leapfrogging"). This prevents any pair of noncentral positions to be an equilibrium. When the firms position at the center with an infinitesimal distance between them, neither firm has an incentive to deviate. Hence, clustering at the market center is the only "noncooperative $^{\prime \prime}$ positional equilibrium (see Proposition 1). It is formally defined as follows: Given prices $p_{i}=p_{i}$ a positional equilibrium (or positional-Nash equilibrium) is a pair $x_{i}^{*}$ and $x_{i}^{*}$ such that

$$
\Pi_{i}\left(x_{i}^{*}, x_{j}^{*}\right) \geq \Pi_{i}\left(x_{i}, x_{j}^{*}\right), \quad \forall x_{i} \in[0,1], \quad i, j=1,2 \text { and } i \neq j .
$$

This definition can be extended easily to the case of $n$ firms competing in position.

The principle of minimum differentiation suggests offering identical products (i.e., a "me too" strategy) under exogenously given prices. This principle has been confirmed by several studies in marketing (Carpenter, 1989; Hauser, 1988; Hauser and Shugan, 1983). With respect to the "Defender Model" (Hauser and Shugan, 1983), Hauser (1988) has recently analyzed a variety of equilibrium implications. He finds support for minimum differentiation under the assumption of identical and constant prices. Carpenter (1989) also suggests minimum differentiation under exogenously given prices. Incorporating advertising and promotion as well as positioning in a two-dimensional market, he claims that offering identical products can be optimal if price competition is restricted and consumer preferences are unimodal.

Minimum differentiation is, however, questionable in a variety of competitive environments as shown in Table I. In general, the literature on product competition under given prices does not support minimum differentiation. The principle is valid only for duopoly under the assumption of inelastic consumer demand. ${ }^{5}$ The principle of minimum differentiation is, nevertheless, restored in a general $n$-firm case with the incorporation of consumer heterogeneity on the unobservable attribute (even when given prices are different). Intuitively, if taste heterogeneity increases along the unobservable attribute, consumer choice is relatively more dependent on the unobservable attribute. Although a product is close to the ideal point on the observable

5. For a more extensive review on product positioning in the Hotelling paradigm, see Jaskold Gabszewicz and Thisse (1986). 


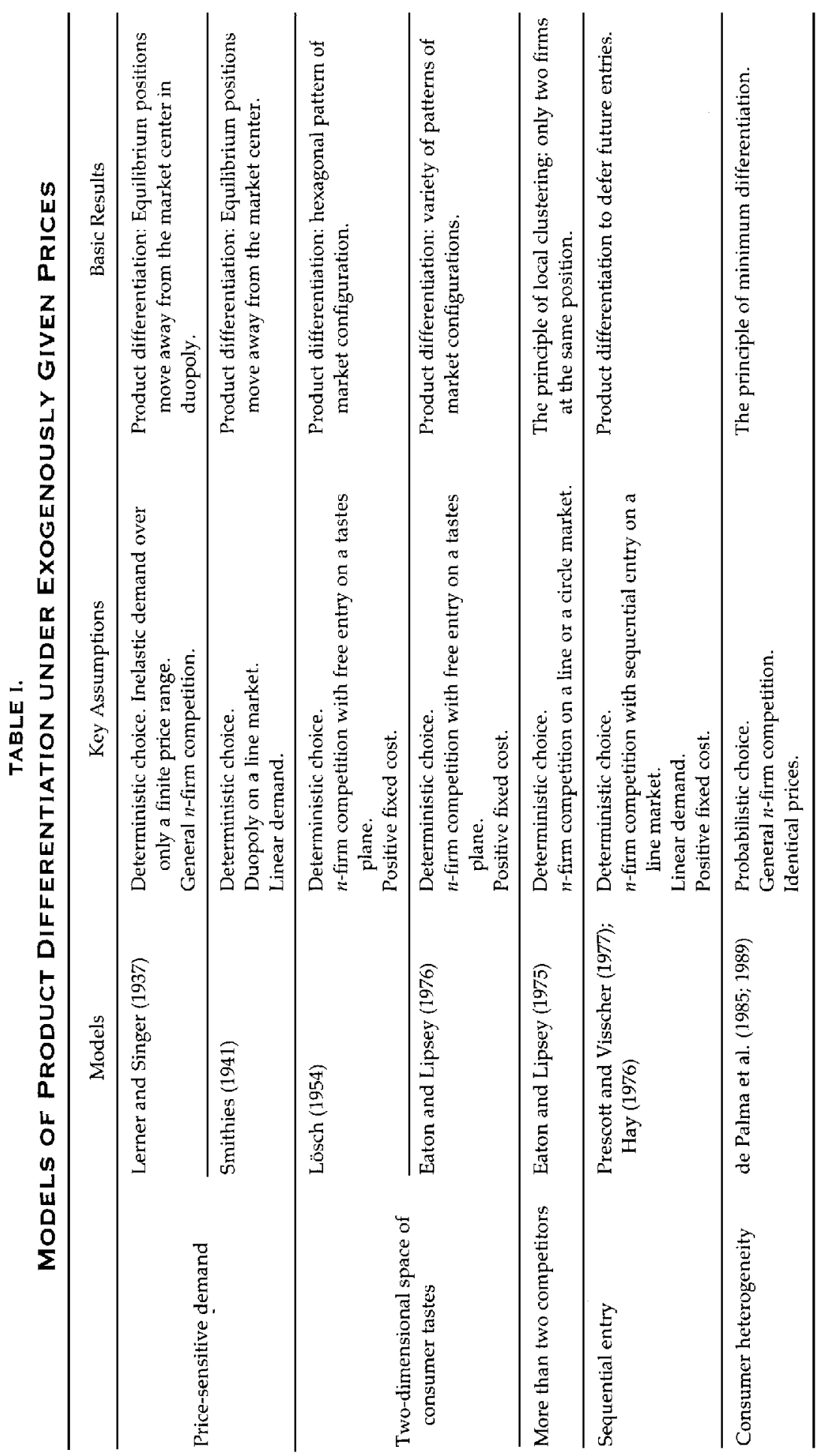


attribute, a consumer will prefer another product that generates a greater utility from the unobservable attribute. Firms may have an incentive to capture those choice heterogeneities (because of the unobservable attribute) across the entire market by positioning at the market center. A formal investigation is presented below.

Proposition 1: Given any positive prices, $p_{1} \ldots p_{n^{\prime}}$ there exists a positional equilibrium at the market center, $x_{1}^{*}=\ldots=x_{n}^{*}=\frac{1}{2}$, provided that

$$
\sigma \geq \frac{\delta}{2}
$$

In the case of identical prices, the equilibrium positions are always at the market center for any $\sigma \geq 0$ when $n=2$.

Proof. see Appendix 1.

The condition given by Proposition 1 is sufficient. It can easily be shown that equilibrium positions are not necessarily at the center for $n \geq 3$ (even with identical prices) or $n=2$ (with different prices) for lower values of $\sigma(\sigma<\delta / 2)$.

Proposition 1 shows that, even in the general $n$-firm case, an agglomerated positional equilibrium at the market center exists under sufficient consumer heterogeneity along the unobservable attribute. Under the assumption of identical prices, de Palma et al. (1985) present a sufficient condition for the existence of the agglomerated equilibrium at the center. It has also been shown that dispersed equilibrium positions under insufficient heterogeneity along the unobservable attribute converge at the market center as $\sigma$ increases (de Palma et al., 1987). That is, congruent with the earlier intuition, each firm prefers to differentiate its product at a quasi-monopolistic position on the observable attribute when faced with low levels of taste heterogeneity along the unobservable attribute (de Palma et al., 1987). If consumer heterogeneity increases along the unobservable attribute, firms will reap the gain by shifting the market center. As shown in Proposition 1, however, the given prices need not be identical to yield these results. As long as price competition is precluded and consumers show sufficient heterogeneities along the unobservable attribute, the firms will position at the market center and the principle of minimum differentiation will prevail.

\section{PRoduct Positioning WITH PRICE COMPETITION IN A DUOPOLY}

When both position and price are strategic variables, competition is usually analyzed in a two-stage game framework ( $d^{\prime}$ Aspremont et al., 
1979; Economides, 1984, 1986; Moorthy, 1988). In the first stage, the firms simultaneously determine position on the observable attribute $X$. After having observed each other's position, the firms set price simultaneously in the second stage. The reasoning is that adjusting price is generally easier than changing position. Because price can easily be adjusted depending on product position, the firms anticipate the impact of their positions on the resulting price competition when choosing a position on the observable attribute. Hence, backward induction is employed to obtain equilibrium positions and prices. Specifically, in the second stage, equilibrium prices are obtained noncooperatively taking positions as given. In the first stage, the firms choose positions on the observable attribute taking into account explicitly the equilibrium prices determined in the second stage.

Before investigating the impact of consumer heterogeneity along the unobservable attribute on positional equilibrium (under price competition), we briefly review the literature on the homogenous case. ${ }^{6}$ The principle of minimum differentiation fails to hold in a two-stage game framework ( $d$ 'Aspremont et al., 1979). If the firms position close to each other, there is no price equilibrium in pure strategies under the assumption of linear utility function. In the last decade, vast amounts of research have been conducted in order to resolve the problem of nonexistence of an equilibrium in pure strategies under relaxed and altered assumptions. ${ }^{7}$ The research can be classified into two streams: modifying (a) the assumptions on consumer utility and tastes distribution, and (b) firms' entries and reactions (the rules of the game). Main contributions are summarized in Table II.

Previous attempts only consider consumer heterogeneity along the observable attribute and not along the unobservable attribute. They suggest product differentiation under various assumptions on consumers' and firms' behavior. Minimum differentiation leads to cutthroat price competition and erodes profits. However, the principle of minimum differentiation is fully restored under sufficient heterogeneity along the unobservable attribute even in a two-stage

6. For a more extensive review on monopolistic competition (Chamberlinian paradigm) and product differentiation (Hotelling paradigm), see Lancaster (1990).

7. An equilibrium in mixed strategies does exist even under the original assumptions of Hotelling (1929) (Dasgupta and Maskin, 1986b). Nonexistence of an equilibrium in pure strategies is due to the violation of the continuity and quasi-concavity conditions of profit function. For such discontinuous profit functions as in Hotelling's (1929), there exists an equilibrium in mixed strategies (Dasgupta and Maskin, 1986a). Although an equilibrium in mixed strategies describes firms' competitive reactions, it has limitations in suggesting an optimal product design and price. Hence, from a marketing perspective, the normative value of a mixed strategy equilibrium is limited. 
game. Intuitively, as consumer choices are increasingly affected by the unobservable attribute, consumers depend less on price when choosing a product. Undercutting competitors' prices is unprofitable. The firms may be better off in a quasi-monopolistic position (i.e., offering distinct products). As taste heterogeneity further increases along the unobservable attribute, choices become more dependent on consumers' valuations of producers along the unobservable attribute. Whereas price competition and differentiation on the observable attribute become relatively less important, the choice heterogeneities caused by consumers' diverse valuations along the unobservable attribute (which are unknown to the firms) increases over the entire market. Hence, the firms may position at the market center to capture those heterogeneities. A formal investigation in the case of duopoly is presented below.

We begin our analysis with price competition given the firms' positions. Price equilibrium is defined, and the effect of heterogeneity along the unobservable attribute on equilibrium prices is investigated. In the subsequent section, we will define positional equilibrium while considering price equilibrium in the second stage. We examine the effect of heterogeneity along the unobservable attribute on the equilibrium positions.

\section{1 PRICE CoMPETITION}

Given $x_{i}$ and $x_{j}$, a price equilibrium is a pair of prices $p_{i}^{*}$ and $p_{j}^{*}$ such that

$$
\Pi_{i}\left(p_{i}^{*}, p_{j}^{*} ; x_{i}, x_{j}\right) \geq \Pi_{i}\left(p_{i}, p_{j}^{*} ; x_{i}, x_{j}\right), \forall p_{i} \geq 0, i, j=1,2 \text { and } i \neq j,
$$

where $\Pi_{i}$ is defined by eq. (2). The following result establishes the existence of price equilibrium in pure strategies when consumer choices are sufficiently heterogeneous along the unobservable attribute.

Proposition 2: Given any pair of positions $x_{i}$ and $x_{i}$ along the observable attribute, there exists $\sigma^{*} \geq 0$ such that, for any $\sigma \geq \sigma^{*}$, there is a unique price equilibrium.

Proof. See Appendix 2.

When $\sigma=0$, d'Aspremont et al. (1979) have shown that price equilibrium (in pure strategies) does not exist when two firms position near each other. The firms engage in a price war where at least one firm undercuts its rival's price to capture the entire market. In the case of identical positions, $x_{i}=x_{i}$, the firms trap themselves into a Bertrand situation in which they sell perfectly homogeneous products and retain 


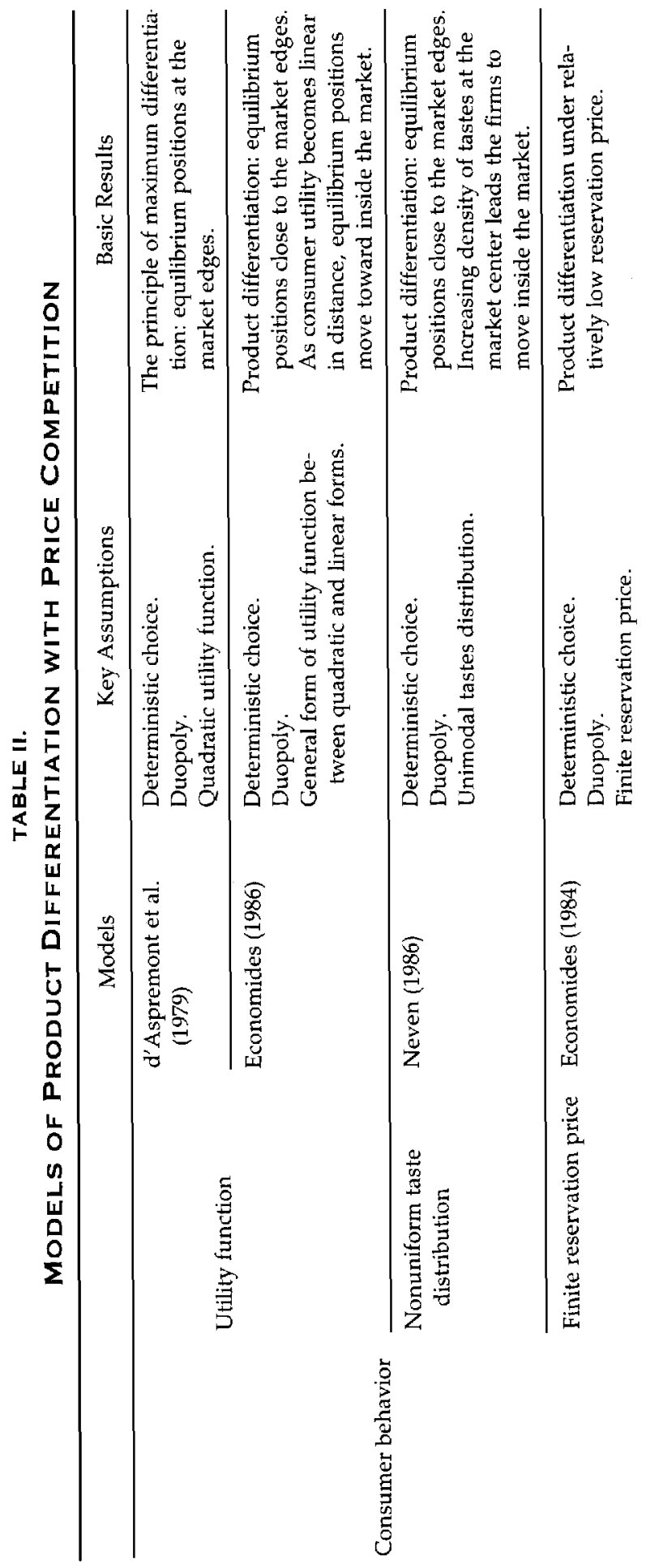




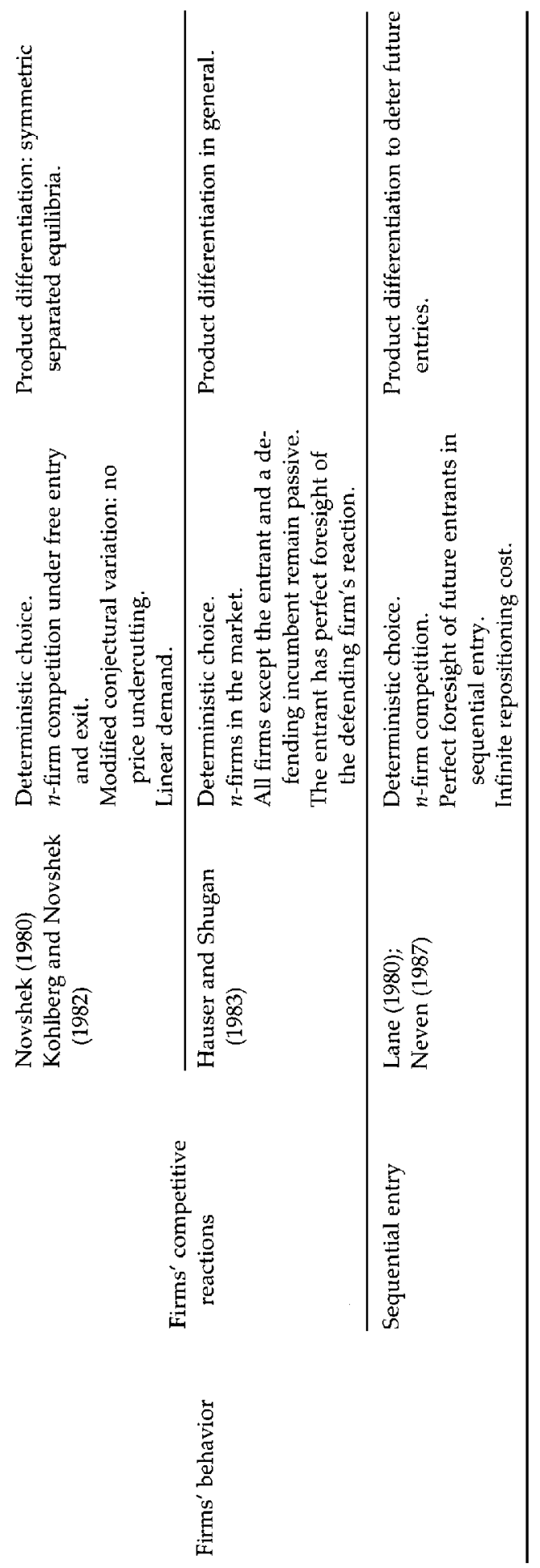


no market power: $p_{i}^{*}=p_{i}^{*}=0$ (i.e., profit margins are zero). If the firms position symmetrically in the market, $x_{j}=1-x_{i}$, equilibrium fails to exist when the positions are distinct but inside the first and third quartiles. When the firms' positions are outside the quartiles, there exists a price equilibrium such that $p_{i}^{*}=p_{i}^{*}=\delta$ (d'Aspremont et al., 1979). This implies that, as the importance weight $\delta$ increases, consumer choices become more dependent on product differentiation along the observable attribute than price. Hence, the firms can charge higher prices and earn greater profits.

A small amount of consumer heterogeneity along the unobservable attribute is not sufficient to prevent a price war. Figure 3 provides the values of $\sigma^{*}$ that are required to obtain a price equilibrium in the case of symmetric positions. $\sigma^{*}$ is zero when $x_{i}$ and $x_{j}$ are outside the quartiles $\left(0 \leq x_{i} \leq 0.25\right)$ or when $x_{i}=x_{i}(=0.5)$.

In the case of symmetric positions, given sufficiently large $\sigma$, equilibrium prices can be obtained from the first-order conditions:

$$
p_{i}^{*}=p_{j}^{*}=\frac{\sigma[\exp (\theta)+1]^{2}}{4 x_{i} \exp (\theta)+(\sigma / \delta)[\exp (2 \theta)-1]}
$$

where

$$
\theta \equiv \frac{\delta}{\sigma}\left(1-2 x_{i}\right)
$$

It can easily be shown that the equilibrium prices are increasing for $\delta$ as in the case of $\sigma=0$. The sensitivity of the equilibrium price regarding $\sigma$ is more interesting: There exists $\hat{\sigma}$ such that

$$
\frac{\partial p_{i}^{*}}{\partial \sigma}>0 \quad \text { for } \quad \sigma \stackrel{<}{>} \hat{\sigma} .
$$

This implies that, when $\sigma$ is not sufficiently large (but large enough to guarantee the existence of the equilibrium), an increase in consumer heterogeneity along the unobservable attribute leads to lower prices. This seems counterintuitive because a large $\sigma$ may be viewed as increasing product differentiation along the unobservable attribute, which, in turn, might increase prices. In fact, increases in $\delta$ and $\sigma$ generate the same effect because both refer to (different types of) attributes. However, given product differentiation on the observable attribute, if $\sigma$ is not sufficiently large $(\sigma<\hat{\sigma})$, each firm loses market power in its market (along the observable attribute) and tends to invade its rival's market by lowering price. This counteractive force defeats the effect of product differentiation on the unobservable attribute and lowers equilibrium 


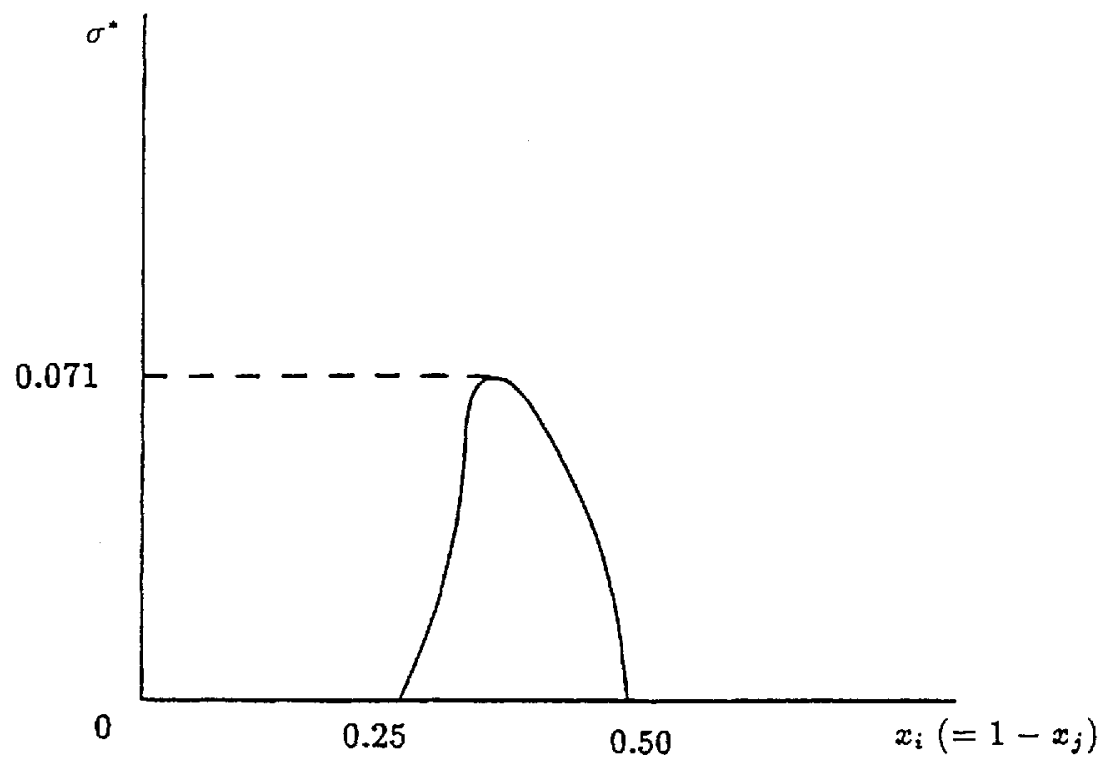

FIGURE 3. THE VALUES OF $\sigma^{*}$ FOR THE EXISTENCE OF SYMMETRIC PRICE EQUILIBRIUM IN PURE STRATEGIES. SYMMETRIC PRICE EQUILIBRIUM EXISTS FOR $\sigma \geq \sigma^{*}$.

prices. On the other hand, when $\sigma$ is sufficiently large ( $\sigma>\hat{\sigma})$, the product differentiation effect (along the unobservable attribute) dominates, and the firms have more leeway to post higher prices. ${ }^{8}$

Because $\partial p_{i}^{*} / \partial x_{i}<0, p_{i}^{*}$ decreases as the "distance" between the firms' positions on the observable attribute decreases. If $x_{i}=x_{j}=\frac{1}{2}$, equilibrium prices become $p_{i}^{*}=p_{j}^{*}=2 \sigma$, which is equivalent to the price equilibrium where products are not differentiated on the observable attribute (Anderson and de Palma, 1992). Because the sensitivity analysis is straightforward, we can safely conclude that the unexpected effect of $\sigma$ on the equilibrium price is due to the interaction between the observable and unobservable attributes.

8. In the case of quadratic utility loss, $\partial p_{i}^{*} / \partial \sigma$ is always positive. The difference in the impact of $\sigma$ on the equilibrium price in the cases of linear and quadratic utility loss reveal the importance of the consumer preference structure on price formation. Although intuition suggests that decreasing equilibrium price for $\sigma$ may not be the rule, careful empirical studies should be pursued in order to gain further insights about the relevance of the two models considered. 


\subsection{POSITIONING COMPETITION}

As shown in the previous section, under sufficient heterogeneity along the unobservable attribute, there exists a unique price equilibrium in pure strategies given any pair of the firms' positions, $x_{i}$ and $x_{i}$. Equilibrium prices, $p_{i}^{*}\left(x_{i}, x_{j}\right)$ and $p_{j}^{*}\left(x_{i}, x_{j}\right)$, are functions of these positions. When we substitute prices in the firms' profits with the equilibrium prices, the firms $s^{\prime}$ profits are solely determined by positions, $x_{i}$ and $x_{i}$ :

$$
\begin{aligned}
& \Pi_{i}\left(x_{i}, x_{j}, p_{i}^{*}\left[x_{i}, x_{j}\right], p_{j}^{*}\left[x_{i}, x_{j}\right]\right) \equiv \Pi_{i}^{*}\left(x_{i}, x_{j}\right) \\
& \Pi_{j}\left(x_{i}, x_{j}, p_{i}^{*}\left[x_{i}, x_{j}\right], p_{j}^{*}\left[x_{i}, x_{j}\right]\right) \equiv \Pi_{j}^{*}\left(x_{i}, x_{j}\right) .
\end{aligned}
$$

Hence, we obtain a noncooperative positional equilibrium, $\left(x_{i}^{*}, x_{i}^{*}\right)$, such that:

$$
\Pi_{i}^{*}\left(x_{i}^{*}, x_{j}^{*}\right) \geq \Pi_{i}^{*}\left(x_{i}, x_{j}^{*}\right), \quad \forall x_{i} \in I, \quad i, j=1,2 \text { and } i \neq j .
$$

Note that the firms' profits depend only upon positions. This implies that, when choosing a product position, the firms anticipate the price equilibrium that will arise at any chosen pair of positions. In particular, firms are aware that price competition will be more intense as two positions get closer. In game-theoretic terms, this means that we need to look for a subgame perfect Nash equilibrium.

Because the firms ${ }^{r}$ profits are determined by positions in the positioning game, the first-order conditions with respect to positions provide equilibrium positions (if any) as well as corresponding equilibrium prices. However, the complexity of this problem makes it difficult to find an analytical solution. We therefore resort to numerical computations. The profits of the firms are computed with a grid size of $10^{-2}$ for $0.01 \leq \sigma / \delta \leq 2.00 . .^{9}$

The following results are obtained.

\section{PROPOSITION 3:}

(a) If $0.06 \leq \sigma / \delta<0.76$, there is no center equilibrium, but symmetrically dispersed equilibria do exist.

(b) If $0.76 \leq \sigma / \delta<1.47$, there are both center and dispersed equilibria, but

9. For each case of $\sigma / \delta$, equilibrium prices are computed with a grid size of $10^{-3}$ for $0.000 \leq x_{i} \leq x_{j}$ and $x_{i} \leq x_{i} \leq 1.000$. Specifically, given $x_{i}$ and $x_{j}$, price equilibrium is obtained via the Newton-Raphson method. The firms' profits and the first derivatives of profits with respect to $x_{i}$ and $x_{i}$ are computed and checked with equilibrium prices to find a positional equilibrium. 
the center equilibrium is not trembling hand perfect.

(c) If $\sigma / \delta \geq 1.47$, there is an equilibrium only at the market center.

Figure 4 describes the three intervals. There is no positional equilibrium for low values of $\sigma$ (i.e., $0 \leq \sigma / \delta<0.06$ ) because price equilibria do not exist. That is, when consumer heterogeneity along the unobservable attribute is negligible, the firms correctly predict each consumer's choice. The firms engage in cut-throat price competition. In the interval $0.06 \leq \sigma / \delta \leq 0.76$, there exist only symmetrically dispersed equilibria. ${ }^{10}$ The implication is that increasing taste heterogeneity along the unobservable attribute reduces consumers' weights on the observable attribute and price in product choice. Hence, price undercutting is unprofitable. However, the increase in the heterogeneity is not sufficient to render price competition and differentiation along the observable attribute ineffective. In equilibrium, the firms offer differentiated products to increase the market power. When $0.06 \leq \sigma / \delta \leq 0.30$, as $\sigma$ increases, dispersed equilibria move toward the edges of the market. Differentiation on the observable attribute is maximized when $\sigma / \delta=0.30$. As $\sigma$ increases in the interval $0.30 \leq \sigma / \delta \leq 0.76$, the dispersed equilibria move toward the inside of the market. This result is consistent with our expectations. As consumer heterogeneity increases along the unobservable attribute, choices become more dependent on the unobservable attribute and less on price and the observable attribute. Hence, market opportunities from the increased choice variations and diminishing competition on price and the observable attribute force the firms to differentiate their products less on the observable attribute.

In the interval $0.76 \leq \sigma / \delta<1.47$, both center and dispersed equilibria exist. The center equilibrium, however, is not trembling hand perfect (Selten, 1975). This equilibrium can exist only under the condition that there is zero probability of choosing a noncentral position. ${ }^{11}$ On the other hand, as $\sigma$ increases, dispersed equilibria converge at the market center. At $\sigma / \delta \geq 1.47$, there is only one equilibrium and it is at the center of the market. This implies that when there

10. There are two dispersed equilibria for the firm i's position to the left and the right of firm $j$.

11. In the numerical computation, when $x_{i}\left(x_{i}\right)$ is fixed at the center, $I I_{i}^{*}\left(\Pi_{i}^{*}\right)$ decreases as $x_{j}\left(x_{i}\right)$ moves away from the center. This implies that neither firm has an incentive to move away from the center (subgame perfect Nash equilibrium). On the other hand, if $x_{i}$ is an infinitesimal distance from the center $\left(10^{-3}\right), I_{i}^{*}$ increases as $x_{i}$ moves away from the center. That is, a small possibility of decision error (trembling hands) forces the firms to leave the center equilibrium. The equilibrium at the market center no longer exists. 


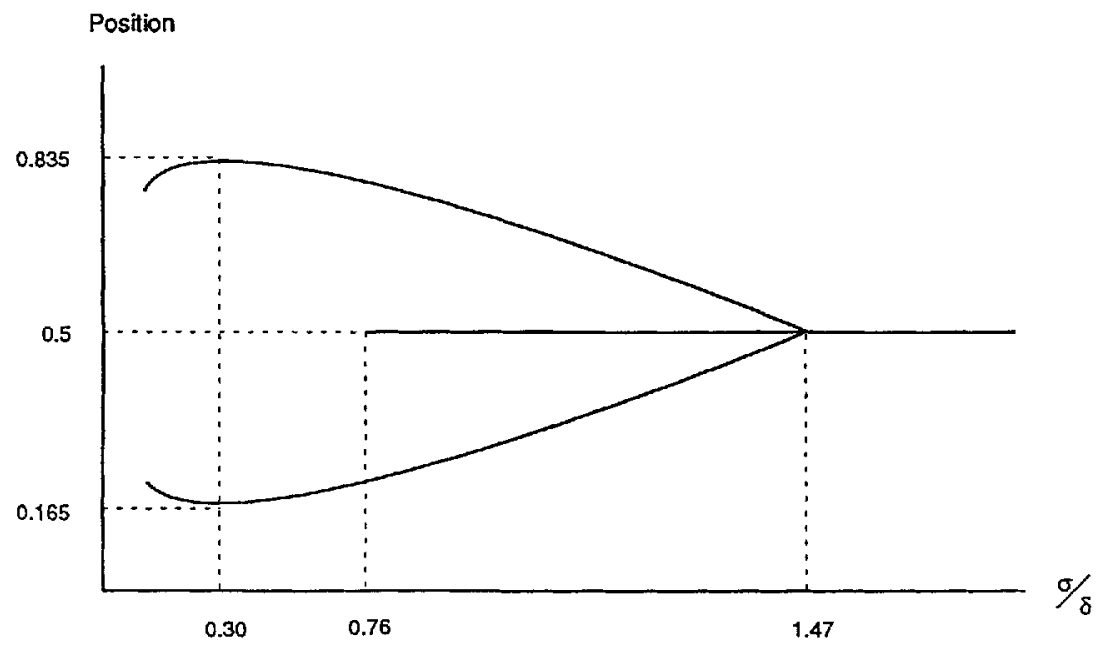

FIGURE 4. EQUILIBRIUM POSITIONS WITH RESPECT TO $\sigma / \delta$.

are sufficient consumer heterogeneities along the unobservable attribute, the firms want to position at the market center to capture those heterogeneities across the entire market. ${ }^{12}$

In equilibrium, both firms have identical prices, profits, and market shares. In general, as consumer heterogeneity increases along the unobservable attribute, the firms can charge higher prices and earn greater profits because consumer choices depend less on price. In the interval $\sigma / \delta \geq 1.47$, equilibrium prices and profits will increase linearly. At the center equilibrium, the firms charge identical prices at $2 \sigma$, and make identical profits of $\sigma$ (as in a binary logit duopoly). When $0.76 \leq \sigma / \delta \leq 1.47$, the dispersed equilibrium produces higher prices and greater profits than the center equilibrium. Prices and profits are at their lowest at $\sigma / \delta=0.16$. When $\sigma / \delta$ is less than 0.16 , equilibrium prices and profits decrease as $\sigma$ increases. This is probably due to the assumption of linear utility loss.

We can easily infer the effect of $\delta$ reflecting the effect of product differentiation along the observable attribute. A small value of $\delta$ implies that consumers pay little attention to the distance between an ideal and a product position on the observable attribute. Consumer

12. A quadratic utility function does not fundamentally alter the positional equilibrium; it only simplifies some of its features. A general discussion in the quadratic case is available from the authors upon request. 
heterogeneity along the unobservable attribute, then, has relatively large effects. As $\delta$ increases, consumer choices are more dependent on the observable attribute. Hence, the effect of consumer heterogeneity along the unobservable attribute is alleviated, and positions tend to diverge from the center.

\section{SUMMARY AND DISCUSSION}

Hotelling introduced a spatial dimension in the analysis of strategic positioning to avoid cut-throat price competition. His finding suggests product standardization--an agglomeration of competitors at the market center. This has come to be known as "the principle of minimum differentiation." Discontinuities in demands, however, eliminate the possibility of a Nash equilibrium in pure strategies. Starting with the 1937 paper by Lerner and Singer, research has continued to point out that equilibrium positions are typically different from those implied by Hotelling's principle. For example, positioning in distinct segments (i.e., product differentiation) is often desirable from the firms' viewpoint because of reduced vulnerability to price cutting. In practice, this would indicate a trend toward more segmentation-not less. Yet, similar products are also often observed in the marketplace.

There have been a handful of attempts to account for standardization (de Palma et al., 1985; 1987). But, as discussed earlier, all of these studies have relied upon rather limiting assumptions. In lieu of the fact that the lion's share of past research views the principle of minimum differentiation as flawed, our contribution is the restoration of this principle under more realistic assumptions than what has previously been done.

When price competition is restricted (even in the case when exogenous prices are competitively chosen), consumer heterogeneity along the unobservable attribute leads to positive profits and minimum differentiation on the observable attribute. Note that our finding is not necessarily limited to the case of duopoly or to the case of identical prices. Even in the case of $n$-firms with unequal prices, taste heterogeneity along the unobservable attribute forces each firm to position close to the competition (on the observable attribute). When the firms are free to set both price and position in duopoly, a Nash equilibrium in pure strategies is found at the center of the market when consumer heterogeneity along the unobservable attribute is sufficiently large. Both firms position at the market center and charge identical prices. On the other hand, under insufficient heterogeneity along the unobservable attribute, our results agree with past research that argues in favor of differ- 
entiation. That is, we obtain consistent results under both exogenously given prices as well as price competition.

These results may explain why there is such a degree of standardization in regulated industries. Under taste heterogeneity along the unobservable attributes, the firms in those industries may be better off positioning close to the competition on the observable attributes. When the firms become deregulated, they are exposed to price competition, which may force the firms to differentiate their products if those heterogeneities are not large enough to produce equilibrium positions at the market center. Examples are found in airlines (Bauer, 1987), motor carriers (Mentzer and Gomes, 1986) and telecommunications industries (Marks, 1988). However, if those heterogeneities are sufficiently large, we expect that even deregulation may not yield product differentiation on the observable attribute. Each firm will remain close to the competition.

The implications of our findings are intriguing and to some extent paradoxical. As noted earlier, firms have difficulty predicting consumer choices as tastes along the unobservable attribute become more heterogeneous. It is then desirable for the firms to offer a product similar to the competition on the observable attribute. This implies that when consumers look for more differentiation along the unobservable attributes (i.e., implicit differentiation), the firms respond to consumers' requests by decreasing strategic differentiation on the observable attributes. Hence, the degree of strategic differentiation decreases when the degree of implicit differentiation increases. The opposite is true when taste heterogeneity along the observable attribute is more salient in product choice: Firms can predict consumer choices with some degree of accuracy and, therefore, capitalize on the known taste heterogeneity among consumers. The firms then differentiate their products in order to capture those heterogeneities on the strategic (observable) attribute as well as to avoid price competition (if price is a strategic variable). That is, decreasing implicit differentiation will lead to increasing strategic differentiation. In other words, there is a trade-off between the two types of differentiation: implicit versus strategic differentiation (except for relatively low values of $\sigma / \delta$ ).

The unknown attribute (or group of attributes) plays an important role when consumers seek variety or when consumer choices are more dependent on situational influences and consumer-specific characteristics that are unknown to the firms. The degree of uncertainty $(\sigma)$ in predicting choices then increases because of the unknown attributes. In addition, the uncertainty also increases when the firms are relatively ignorant about consumer behavior and preferences. Under these circumstances, we would expect more standardization on the 
strategic attribute. Decreasing strategic differentiation for greater implicit differentiation may, however, yield a lower level of consumer satisfaction for the firms' offerings. As the firms' uncertainty $(\sigma)$ increases, equilibrium positions approach each other along the strategic attribute, and equilibrium prices increase. Hence, the aggregate consumer utility loss ${ }^{13}$ over the entire market increases. It has been shown in consumer satisfaction research that satisfaction is expressed as a function of not only prepurchase expectations but also postpurchase perceived performance of the product. (For an extensive review, see $\mathrm{Yi}, 1990$.$) Although more theoretical and empirical re-$ search needs to be pursued, it would seem that consumer utility loss is inversely related to consumer satisfaction. Under this conjecture, increasing consumer utility loss may cause a lower level of consumer satisfaction.

Recent empirical findings seem to support this reasoning. Consumer satisfaction has been found to be lacking in markets where buyer tastes are heterogeneous and the supply is standardized (Fornell, 1992). A plausible explanation for standardization is the lack of knowledge about consumer preference diversity on the part of the firms. Although a significant portion of the heterogeneous preferences may be captured on the strategic attribute, firms seem to treat those diverse preferences as heterogeneous tastes along the unknown attributes because of lack of marketing knowledge and research skills. If this is true, there may be significant gains for the firm that breaks away from the mold by reducing the level of uncertainty with respect to the unknown attributes. Such a reduction in uncertainty may be accomplished through marketing research. Although the evidence is far from clear, this is consistent with what seems to occur in banking, automobile dealerships, airlines, and insurance industries, to mention a few. From a fairly standardized set of offerings often coupled with low consumer satisfaction, at least some firms in these industries are now using more marketing research and seem to be moving toward differentiation. As the firms become more proficient in countering uncertainty, minimum differentiation will no longer be optimal. As a result, aggregate consumer satisfaction may also increase.

Our findings may seem to fly in the face of the typical textbook

13. A consumer of type $(x, y)$ bears the utility loss, $p_{i}+\delta\left|x_{i}-x\right|+e_{i}(y)$ in consuming a unit of product $i$. The aggregate consumer utility loss is defined as the integral of individual consumer utility losses (in consuming their chosen products) over the entire market. 
advice that different tastes should be met by differentiation and segmentation. However, the intuition behind our results is straightforward: Unless consumer tastes are heterogeneous and reasonably predictable, standardization on the strategic attribute will pay off because firms try to capture those heterogeneities across the entire market. On the other hand, decreasing degree of strategic differentiation may lead to a lower level of consumer satisfaction because the discrepancy between what they desire and what they obtain becomes larger. Marketing research should be conducted in order to better understand consumer behavior and preferences and to improve the level of consumer satisfaction.

In conclusion, it seems appropriate to provide some caveats. Our results are limited in several respects. They are confined to the case of duopoly for the investigation of positioning with price competition (two-stage game). From de Palma et al.'s (1987) results, however, we conjecture that the effects will be the same when there are more firms in the market. We also assume a consumer model in the Coombsian (1950) sense following the tradition of Hotelling (1929). The effects could also be analyzed when consumers have a quality (e.g., Jaskold Gabszewicz and Thisse, 1979; Moorthy, 1988; Shaked and Sutton, 1982) or a combined type utility model (e.g., Neven and Thisse, 1990). Although past research on firms' quality decisions suggests differentiation (Moorthy, 1988; Shaked and Sutton, 1982), Rhee (1989) has shown that under sufficient heterogeneity along the unobservable attributes, competing firms will produce similar quality products (which is consistent with the results of this paper).

\section{APPENDIX 1}

Proof of Proposition 1. When $x_{2}=x_{3}=\ldots=x_{n}=\frac{1}{2}$ and $x_{1}<\frac{1}{2}$, firm 1 's expected profit is

$$
\Pi_{1}=p_{1}\left[a^{\prime \prime} x_{1}+\frac{b^{\prime \prime}}{2}+\frac{1}{2}\left(1-2 x_{1}\right)-\frac{\sigma}{2 \delta} \ln \left(\frac{a^{\prime \prime}}{b^{\prime \prime}}\right)\right]
$$

where

$$
\begin{aligned}
& a^{\prime \prime} \equiv\left\{1+\sum_{j=2}^{n} \exp \left[\frac{\left(p_{1}-p_{j}\right)}{\sigma}-\frac{\delta}{2 \sigma}\left(1-2 x_{1}\right)\right]\right\}^{-1} \\
& b^{\prime \prime} \equiv\left\{1+\sum_{j=2}^{n} \exp \left[\frac{\left(p_{1}-p_{j}\right)}{\sigma}+\frac{\delta}{2 \sigma}\left(1-2 x_{1}\right)\right]\right\}^{-1}
\end{aligned}
$$


From the profit function, we obtain

$\operatorname{Sign} \frac{\partial \Pi_{1}}{\partial x_{1}}=\operatorname{Sign}\left[\begin{array}{c}\delta E(E+S)^{2}+\sigma\left(E^{2}-1\right)(E+S)(1+S E) \\ \left.-2 \delta E(1+S E)^{2} x_{1}\right]\end{array}\right.$

where

$$
S=\sum_{j=2}^{n} \exp \left[\frac{p_{1}-p_{j}}{\sigma}\right] \quad \text { and } \quad E \equiv \exp \left[\frac{\delta}{2 \sigma}\left(1-2 x_{1}\right)\right] .
$$

The market center is an equilibrium if $\partial \Pi_{1} / \partial x_{1}>0$ for $0 \leq x_{1}<\frac{1}{2}$. This condition is satisfied if the lower bound of eq. (1.2) is positive. When $\sigma \geq \delta / 2$,

$$
\begin{gathered}
\delta E(E+S)^{2}+\sigma\left(E^{2}-1\right)(E+S)(1+S E)-2 \delta E(1+S E)^{2} x_{1} \\
\geq \delta E(E+S)^{2}+\frac{\delta}{2}\left(E^{2}-1\right)(E+S)(1+S E)-2 \delta E(1+S E)^{2} x_{1} \\
=\frac{\delta}{2}\left[E\left\{1+E^{2}\left(1-4 x_{1}\right)\right\} S^{2}+\left\{\left(E^{4}-1\right)+4 E^{2}\left(1-2 x_{1}\right)\right\} S\right. \\
\left.+E\left\{3\left(E^{2}-1\right)+2\left(1-2 x_{1}\right)\right\}\right]
\end{gathered}
$$

Equation (A1.3) is always positive for $0 \leq x_{1}<\frac{1}{2}$ regardless of $S$ because

$$
1+E^{2}\left(1-4 x_{1}\right) \geq 0 \quad \text { if } \quad \frac{\delta}{2 \sigma} \leq 1 .
$$

Therefore, the sufficient condition for an equilibrium at the market center is

$$
\sigma \geq \frac{\delta}{2} \text {. }
$$

\section{APPENDIX 2}

Proof of Proposition 2. If $\delta=0$ in the linear case, firm $i$ 's expected profit is

$$
\tilde{\Pi}_{i}=\frac{p_{i}}{1+\exp \left[\left(p_{i}-p_{j}\right) / \sigma\right]} .
$$

The profit function is strictly quasi-concave in $p_{i}$ for any $p_{i}$ (Anderson and de Palma, 1992). At the price equilibrium, $p_{i}^{*}=p_{j}^{*}=2 \sigma$, we have $\partial^{2} \Pi_{i} / \partial p_{i}^{2}<0$. It is assumed that $p_{i}, p_{j} \in[0, Y]$ where $Y$ is consumer income. Note that the marginal costs are normalized to zero. Hence, firm $i$ 's best reply function, $R_{i}\left(p_{j}\right)$, is continuous over $[0, Y]$. By continu- 
ity, there exists a region $C_{0} \subset[0, Y]^{2}$ over which $\partial^{2} \tilde{\Pi}_{i} / \partial p_{i}^{2}<0, \forall p_{i} p_{j} \in$ $C_{0}$. By definition, $R_{i}\left(p_{j}\right)$ is interior to $C_{0}$. (We can always choose a sufficiently large $Y$.) Define $C_{1}$ where $\partial \tilde{\Pi} / \partial p_{i}>0$. Similarly, $C_{2}$ is defined as a region over which $\partial \tilde{\Pi}_{i} / \partial p_{i}<0$. Therefore, the three regions, $C_{0}, C_{1}$, and $C_{2}$, form partitions of $[0, Y]^{2}$, that is, $C_{0} \cup C_{1} \cup C_{2}=[0, Y]^{2}$. Figure A.1 illustrates these three regions.

Given that the profit function $\Pi_{i}$ [defined by eq. (2)] is continuous and twice differentiable with respect to $\delta$, there exists a sufficiently small $\epsilon_{i}$ such that, for any $\delta \in\left[0, \epsilon_{i}\right]$,

$$
\begin{aligned}
& \frac{\partial^{2} \Pi_{i}}{\partial p_{i}^{2}}<0 \text { for } p_{i}, p_{j} \in C_{0} \\
& \frac{\partial \Pi_{i}}{\partial p_{i}}>0(<0) \text { for } p_{i}, p_{i} \in C_{1}\left(\in C_{2}\right) .
\end{aligned}
$$

The previous conditions imply that $\Pi_{i}$ is strictly quasi-concave in $p_{i}$ over $[0, Y]$ for $\delta \in\left[0, \epsilon_{i}\right]$. By the same procedure, it follows that $\Pi_{i}$ is strictly quasi-concave in $p_{j}$ over $[0, Y]$ for $\delta \in\left[0, \epsilon_{i}\right]$. Therefore, the existence of price equilibrium emerges for $\epsilon \leq \min \left[\epsilon_{i}, \epsilon_{j}\right]$ (see Friedman, 1990).

We can easily show that the slopes of the best reply functions

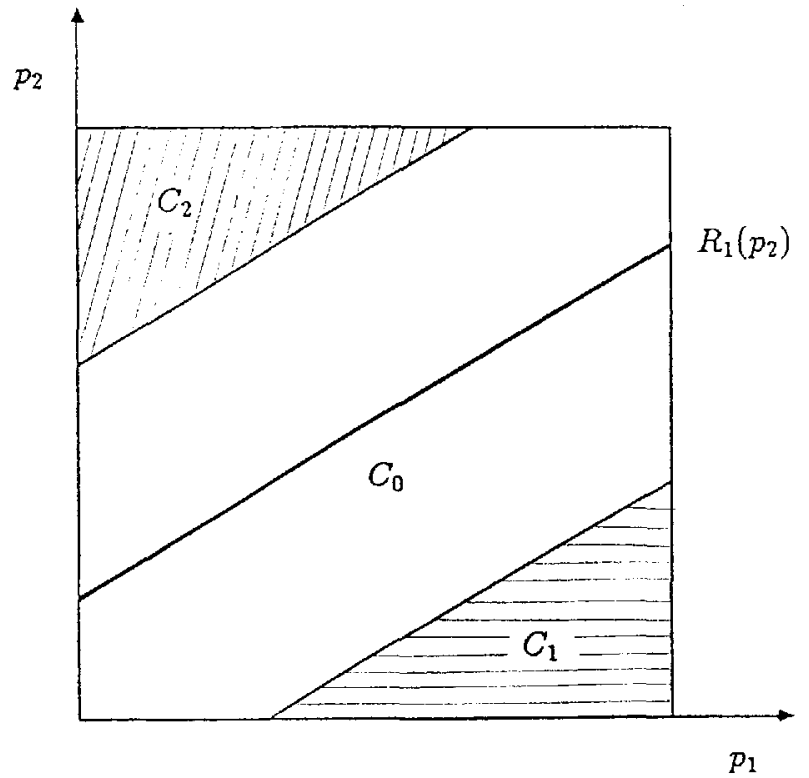

FIGURE A.1. THREE REGIONS, $C_{0}, C_{1}, A N D C_{2}$ OF $[0, Y]^{2}$. 
$\bar{R}_{i}\left(p_{i}\right)$ and $\tilde{R}_{i}\left(p_{i}\right)$ corresponding to $\tilde{\Pi}_{i}$ and $\tilde{\Pi}_{j}$ [defined by eq. (A2.1)] are strictly smaller than 1 over $[0, Y]$. By continuity, the slopes of the best reply functions $R_{i}\left(p_{i}\right)$ and $R_{j}\left(p_{i}\right)$ are strictly smaller than 1 over $[0, Y]$ for $\delta \in[0, \epsilon]$ if $\epsilon$ is sufficiently small. This guarantees uniqueness.

\section{REFERENCES}

Anderson, S.P. and A. de Palma, 1992, "The Logit as a Model of Product Differentiation," Oxford Economic Papers, 44, 51-67.

- - , and J.-F. Thisse, 1988, "A Representative Consumer Theory of the Logit Model," International Economic Review, 29, 461-466.

$\longrightarrow, \ldots$, and $\longrightarrow, 1989$, "Demand for Differentiated Products, Discrete Choice Models, and the Characteristics Approach," Review of Economic Studies, 56, 21-35.

Bass, F.M., A. Jeuland, and G.P. Wright, 1976, "Equilibrium Stochastic Choice and Market Penetration Theories: Derivation and Comparisons," Management Science, 22, 1051-1063.

Bauer, P.W., 1987, "Airline Hubs: A Study of Determining Factors and Effects, Economic Review, 4th Quarter, 13-19.

Ben-Akiva, M. and S. Lerman, 1985, Discrete Choice Analysis: Theory and Applications to Trazel Demand, Cambridge, MA: The MIT Press.

Boyer, K.D., 1977, "Minimum Rate Regulation, Moral Split Sensitivities and the Railroad Problem," Joumal of Political Economy, 85, 493-512.

Carpenter, G.S., 1989, "Perceptual Position and Competitive Brand Strategy in a TwoDimensional, Two-Brand market," Management Science, 35, 1029-1044.

Coombs, C.H., 1950, "Psychological Scaling without a Unit of Measurement," Psychological Review, 57, 148-158.

Daganzo, C., 1979, Multinomial Probit: The Theory and Its Applications to Demand Forecasting, San Francisco: Academic Press.

Dasgupta, P. and E. Maskin, 1986a, "The Existence of Equilibrium in Discontinuous Economic Games, I: Theory," Review of Economic Studies, 53, 1-26.

-_ and __ 1986b, "The Existence of Equilibrium in Discontinuous Economic Games, II: Application," Review of Economic Studies, 53, 27-41.

d'Aspremont, C., J. Jaskold Gabszewicz, and J.-F. Thisse, 1979, "On Hotelling's Stability in Competition," Econometrica, 47, 1145-1150.

de Palma, A., V. Ginsburgh, M. Labbé, and J.-F. Thisse, 1989, "Competitive Location with Probabilistic Choice Model," Transportation Science, 23, 244-252.

de Palma, A., — , Y.Y. Papageorgiou, and J.-F. Thisse, 1985, "The Principle of Minimum Differentiation holds under Sufficient Heterogeneity," Econometrica, 53, $767-781$.

—_ - and J.-F. Thisse, 1987, "On Existence of Location Equilibria in the 3-Firm Hotelling Problem," The Journal of Industrial Economics, 36, 245-252.

DeSoete, G., J.D. Carroll, and W.S. DeSarbo, 1986, "The Wandering Ideal Point Model: A Probabilistic Multidimensional Unfolding Model for Paired Comparisons Data," Journal of Mathematical Psychology, 30, 28-41.

Dixit, A.K. and J.E. Stiglitz, 1977, "Monopolistic Competition and Optimum Product Diversity," American Economic Review, 67, 297-308.

Eaton, B.C. and R.G. Lipsey, 1975, "The Principle of Minimum Differentiation Reconsidered: Some New Developments in the Theory of Spatial Competition," Review of Economic Studies, 42, 27-50. 
and — 1976, "The Non-Uniqueness of Equilibrium in the Löschian Location Model," The American Economic Review, 66, 77-93.

Economides, N., 1984, "The Principle of Minimum Differentiation Revisited," European Economic Review, 24, 345-368.

- 1986, "Minimal and Maximal Product Differentiation in Hotelling's Duopoly," Economic Letters, 21, 67-71.

Eliashberg, J. and R. Chatterjee, 1985, "Analytical Models of Competition with Implications for Marketing: Issues, Findings, and Outlook," Journal of Marketing Research, $22,237-261$.

Fornell, C., 1992, "A National Customer Satisfaction Barometer: The Swedish Experience," Journal of Marketing, 56, 6-21.

Friedman, J., 1990, Game Theory with Applications to Economics, 2nd ed., Oxford, UK: Oxford University Press.

Guadagni, P.M. and J.D.C. Little, 1983, "A Logit Model of Brand Choice," Marketing Science, 2, 203-238.

Hauser, J.R., 1988, "Competitive Price and Positioning Strategies," Marketing Science, 7 , $76-91$.

_ and S.H. Shugan, 1983, "Defensive Marketing Strategies," Marketing Science, 2, 319-360.

Hay, D.A., 1976, "Sequential Entry and Entry-Deterring Strategies in Spatial Competition," Oxford Economic Papers, 240-257.

Hogarth, R.M., 1987, Judgment and Choice; The Psychology of Decision, 2nd ed., New York: John Wiley \& Sons.

Hotelling, H., 1929, "Stability of Competition," The Economic Journal, 39, 41-57.

Ippolito, R.A., 1979, "The Effects of Price Regulation in the Automobile Insurance Industry," Joumal of Law and Economics, 22, 55-89.

—_ and R.T. Masson, 1978, "The Social Cost of Government Regulation of Milk," Journal of Law and Economics, 21, 33--65.

Jaskold Gabszewicz, J. and J.-F. Thisse, 1979, "Price Competition, Quality, and Income Disparities," Journal of Economic Theory, 20, 340-359.

—_ and ——, 1986, "Spatial Competition and the Location of Firms," in R. Arnott, eds., Location Theory, New York: Harwood Academic Publishers, 1-71.

Joskow, P.L. and R. Noll, 1981, "Regulation in Theory and Practice: An Overview," in G. Fromm, ed., Studies of Public Regulation, Cambridge, MA: The MIT Press, 1-77.

Kamakura, W.A. and R.K. Srivastava, 1986, "An Ideal-Point Probabilistic Choice Model for Heterogeneous Preferences," Marketing Science, 5, 199-218.

Kohlberg, E. and W. Novshek, 1982, "Equilibrium in a Simple Price-Location Model," Economics Letters, 9, 7-15.

Kotler, P., 1991, Marketing Management, 7th ed., Englewood Cliffs, NJ: Prentice-Hall.

Lancaster, K., 1979, Variety, Equity, and Efficiency, Oxford, UK: Basil Blackwell.

— 1990, "The Economics of Product Variety: A Survey," Marketing Science, 9, 189206.

Lane, W.J., 1980, "Product Differentiation in a Market with Endogenous Sequential Entry," The Bell Joumal of Economics, 33, 237-260.

Lerner, A.P. and H.W. Singer, 1937, "Some Notes on Duopoly and Spatial Competition," The Journal of Political Economy, 45, 145-186.

Lösch, A., 1954, The Economics of Location, New Haven, CT: Yale University Press.

Luce, R.D., 1959, Individual Choice Behavior: A Theoretical Analysis, Englewood Cliffs, NJ: Prentice-Hall.

MacAvoy, P.W. and R.S. Pindyck, 1973, "Alternative Regulatory Policies for Dealing with the Natural Gas Shortage," The Bell Journal of Economics, 4, 454-498. 
Manski, C., 1977, "The Structure of Random Utility Models," Theory and Decision, 8, 229-254.

Marks, J., 1988, "State Telecommunications Regulation: Success or Failure," Rural Telecommunications, 7, 46-50.

McAlister, L., 1982, "A Dynamic Attribute Satiation Model of Variety-Seeking Behavior," Journal of Consumer Research, 9, 141-150.

McFadden, D., 1974, "Conditional Logit Analysis of Qualitative Choice Behavior," in P. Zarembreka, ed., Frontiers in Econometrics, New York: Academic Press, 105-142.

Mentzer, J.T. and R. Gomes, 1986, "Deregulation of the Motor Carrier Industry: A Retrospective Analysis," International Journal of Physical Distribution on Material Management, 16, 46-58.

Moorthy, K.S., 1985, "Using Game Theory to Model Competition," Journal of Marketing Research, 22, 262-282.

- 1988, "Product and Price Competition in a Duopoly," Marketing Science, 7, 141168.

Neven, D.H., 1986, "On Hotelling's Competition with Non-Uniform Customer Distributions," Economics Letters, 21, 121-126.

__ 1987, "Endogenous Sequential Entry in a Spatial Model," International Journal of Industrial Organization, 5, 419-434.

- and J.-F. Thisse, 1990, "On Quality and Variety Competition," in J. Jaskold Gabszewicz, J.-F. Richard, and L.A. Wolsey, eds., Economic Decision-Making: Games, Econometrics and Optimization, Amsterdam: North-Holland, 175-199.

Novshek, W., 1980, "Equilibrium in Simple Spatial (or Differentiated Product) Models," Journal of Economic Theory, 22, 313-326.

Porter, M.E., 1980, Competitive Strategy, New York: The Free Press.

Prescott, E.C. and M. Visscher, 1977, "Sequential Location among Firms with Foresight," The Bell Journal of Economics, 8, 378-393.

Punj, G.N. and R. Staelin, 1978, "The Choice Process for Graduate Business Schools," Journal of Marketing Research, 15, 588-598.

Rhee, B.-D., 1989, "Consumer Choice Variation and Strategic Quality Decisions," TIMS/ORSA Conference, Fall, New York.

Schmalensee, R., 1977, "Comparative Static Properties of Regulated Airline Oligopolies," The Bell Journal of Economics, 8, 565-576.

__ and J.-F. Thisse, 1988, "Perceptual Maps and the Optimal Location of New Products: An Integrative Essay," International Journal of Research in Marketing, 5, 225-249.

Selten, R., 1975, "Reexamination of the Perfectness Concept for Equilibrium Points in Extensive Games," International Journal of Game Theory, 4, 25-55.

Shaked, A. and J. Sutton, 1982, "Relaxing Price Competition through Product Differentiation," Review of Economic Studies, 49, 3-13.

Smithies, A., 1941, "Optimum Location in Spatial Competition," The Journal of Political Economy, 49, 423-439.

Spence, A.M., 1976, "Product Selection, Fixed Costs, and Monopolistic Competition," Review of Economic Studies, 43, 217-235.

Thurstone, I., 1927, "A Law of Comparative Judgment," Psychological Review, 34, 273286.

Wilkie, W.L. and E.A. Pessemier, 1973, "Issues in Marketing's Use of Multi-Attribute Attitude Models," Journal of Marketing Research, 10, 428-441.

Yi, Y., 1990, "A Critical Review of Consumer Satisfaction," in V.A. Zeithaml, ed., Review of Marketing, Chicago, IL: American Marketing Association, 68-123. 